\title{
Markers of thrombogenesis are activated in unmedicated patients with acute psychosis: a matched case control study
}

\author{
Jiři Masopust ${ }^{*}$, Radovan Malý ${ }^{2}$, Ctirad Andrýs ${ }^{3}$, Martin Vališ ${ }^{4}$, Jan Bažant ${ }^{1}$, Ladislav Hosák ${ }^{1}$
}

\begin{abstract}
Background: Antipsychotic treatment has been repeatedly found to be associated with an increased risk for venous thromboembolism in schizophrenia. The extent to which the propensity for venous thromboembolism is linked to antipsychotic medication alone or psychosis itself is unclear. The objective of this study was to determine whether markers of thrombogenesis are increased in psychotic patients who have not yet been treated with antipsychotic medication.

Methods: We investigated the plasma levels of markers indicating activation of coagulation (D-dimers and Factor VIII) and platelets (soluble P-selectin, sP-selectin) in an antipsychotic-naive group of fourteen men and eleven women with acute psychosis (age $29.1 \pm 8.3$ years, body mass index $23.6 \pm 4.7$ ), and twenty-five healthy volunteers were matched for age, gender and body mass index.

Results: D-dimers (median 0.38 versus $0.19 \mathrm{mg} / \mathrm{l}$, mean $1.12 \pm 2.38$ versus $0.28 \pm 0.3 \mathrm{mg} / \mathrm{l} ; \mathrm{P}=0.003$ ) and $\mathrm{sP}$ selectin (median 204.1 versus $112.4 \mathrm{ng} / \mathrm{ml}$, mean $209.9 \pm 124$ versus $124.1 \pm 32 ; \mathrm{P}=0.0005$ ) plasma levels were significantly increased in the group of patients with acute psychosis as compared with healthy volunteers. We found a trend (median 148\% versus 110\%, mean $160 \pm 72.5$ versus $123 \pm 62.5 ; \mathrm{P}=0.062$ ) of increased plasma levels of factor VIII in psychotic patients as compared with healthy volunteers.

Conclusions: The results suggest that at least a part of venous thromboembolic events in patients with acute psychosis may be induced by pathogenic mechanisms related to psychosis rather than by antipsychotic treatment. Finding an exact cause for venous thromboembolism in psychotic patients is necessary for its effective treatment and prevention.
\end{abstract}

\section{Background}

Schizophrenia is a chronic mental disorder that affects about $1 \%$ of people worldwide. The disease tends to begin when patients are young and results in a shortened life span. Indeed, the life span among patients with schizophrenia is $20 \%$ shorter than that of the general population (61 versus 76 years, on average). Approximately $40 \%$ of mortality in schizophrenia is due to "unnatural causes", such as suicide or accidents. Somatic disorders represent the remaining $60 \%$ of "natural causes" [1].

\footnotetext{
* Correspondence: masopjir@seznam.cz

'Dept. of Psychiatry, Charles University in Prague, Faculty of Medicine in Hradec Králové, and University Hospital Hradec Králové, Czech Republic Full list of author information is available at the end of the article
}

Patients with schizophrenia have higher rates of somatic morbidity and mortality when compared with the general population [2]. This is generally explained by an unhealthy lifestyle, poor dietary habits, and the use of antipsychotic medication [3]. Physical morbidity and mortality in schizophrenia have recently been found to be increasing [4-6].

The risk for cardiovascular mortality among those with schizophrenia is increased twofold as compared with patients without schizophrenia [3]. Of the modifiable risk factors, obesity, smoking, hypertension and dyslipidemia are the most common [4].

Venous thromboembolism (VTE), which is clinically manifest as a deep vein thrombosis (DVT) or a pulmonary embolism (PE), is a multifactorial disease. The primary symptom of DVT is asymmetrical oedema of the

\section{Biomed Central}


limb, while chest pain, breathlessness, haemoptysis, syncope or tachycardia are the most important signs for pulmonary embolism [7]. The incidence of all types of thrombosis are strongly dependent on age. Among individuals up to 40 years of age, venous thromboembolism is the most common form of thrombosis. VTE is also the most common cause of morbidity and mortality in people under 40 years of age [8]. Risk factors for VTE work in the sense of the Virchow's triad: reduced blood flow, changes in the vessel wall, and changes in blood composition [9]. Most of the risk factors for thrombosis fall in the first (stasis) and third (changes in blood coagulability) group. The classification has recently changed and includes genetic and acquired VTE risk factors [8]. Cardiovascular mortality, including death from VTE, has recently become a topic of wide study among patients with schizophrenia because the safety of the treatment and the patient's quality of life are considered more important than in the past [10]. Clinically, it is important that patients treated with antipsychotic medications be treated for metabolic and cardiovascular disease and that collaborations with primary care physicians, diabetes specialists, and cardiologists be established to facilitate appropriate medical care for these patients $[11,12]$.

Antipsychotic medication is associated with an increased risk for VTE [13]. This has been specifically shown in the low-potent first generation antipsychotics or clozapine [14-18]. There has also been increasing evidence concerning the relationship between second generation antipsychotics (olanzapine, risperidone) and VTE [19-23]. On the other hand, schizophrenia or bipolar affective disorder themselves are associated with VTE due to the increased prevalence of a sedentary lifestyle and lack of movements in this population. Obesity, sedation, hyperprolactinemia [24] or acute epinephrine secretion [25] are all factors that increase the likelihood of forming blood clots and are other important VTE risk factors seen in patients with acute psychosis. The risk of VTE is specifically increased in patients who are hospitalised or in physical restraints. The role of antipsychotic medications versus the presence of the mental disorder itself in the aetiology of VTE has not been fully clarified in patients with schizophrenia or other psychoses [26].

The primary aim of the study was to determine whether markers of thrombogenesis (D-dimers, blood factor VIII) and thrombocyte activation (sP-selectin) were activated in unmedicated patients with acute psychosis as compared with matched healthy volunteers.

\section{Methods}

\section{Subjects}

The patients were recruited for the study at the Dept. of Psychiatry, University Hospital in Hradec Králové. Inclusion criteria were as follows: hospitalised patients with acute psychosis (schizophrenia F20, delusional disorder F22, acute schizophreniform psychosis F23.2 according to the ICD-10 classification [27]), age between 18-55 years, unmedicated with antipsychotics, without serious medical comorbidities or a history of VTE. We excluded patients with pre-existing cardiovascular, pulmonary or neurological disease by reviewing the patients' medical records. We also conducted a comprehensive physical and laboratory check-up. This was supplemented by obtaining the patients' family history.

Healthy volunteers were recruited from the staff at the University Hospital in Hradec Králové. Healthy volunteers without any mental or serious somatic disorder were matched to the sample with respect to age, gender, weight, and body mass index (BMI). The possibility of mental illness among the volunteers was excluded by using a psychiatric examination. All participants voluntarily signed the "informed consent" form.

\section{Laboratory examinations}

Venous blood from both the patients and healthy volunteers was taken between 7 and 9 AM after twelve hours of fasting. Laboratory examinations for markers of thrombogenesis and platelet activation are described in Table 1.

\section{Statistical analysis}

We compared values of descriptive statistics (age, gender, weight, body mass index) between the patients and healthy controls using the Student's t-test. As for laboratory assessments in patients versus healthy volunteers, we used the Mann-Whitney U Test and Student's t-test.

\section{Ethical aspects}

All aspects of the present study were approved by the Ethical Committee of the University Hospital in Hradec Králové. Even if patients signed the written "Informed Consent" in a state of acute psychosis, all also agreed to continue in the study in remission later on.

\section{Results}

Twenty-five (women $\mathrm{N}=11$ ) patients with acute psychosis (schizophrenia $\mathrm{N}=19$; acute schizophreniform

\section{Table 1 Laboratory examinations}

\begin{tabular}{cc}
\hline Marker & Method \\
\hline D-dimers & $\begin{array}{c}\text { STA LIA-test }{ }^{\oplus} \text { D-DI (Diagnostica Stago) } \\
\text { Normal values: }<0.5 \mathrm{mg} / \mathrm{l}\end{array}$ \\
\hline Factor VIII & DG-F VIII (Grifols) \\
APTT (C.K. PREST, Diagnostica Stago) \\
Normal values: $50-150 \%$ of the factor activity
\end{tabular}

APTT - activated partial thromboplastin time; ELISA - enzyme-linked immunosorbent assay; LIA - isoturbidimetric method 
psychosis $\mathrm{N}=5$; delusional disorder $\mathrm{N}=1$ ) were included in the study. The control subjects were matched to the patients with respect to age, gender, weight, and body mass index. We did not find any significant demographic difference between the patients and healthy volunteers ( $\mathrm{P}=\mathrm{NS}$; Student's t-test). Demographic data on patients and healthy volunteers are shown in Table 2.

Plasma levels of D-dimer and sP-selectin were significantly higher in the patients as compared with the healthy volunteers $(\mathrm{U}=157,000 ; \mathrm{p}=0.003$ and $\mathrm{U}=$ 133,$000 ; \mathrm{p}=0.0005$, respectively; Mann-Whitney $U$ Test). The plasma level of D-dimer was pathologically increased $(>0.5 \mathrm{mg} / \mathrm{l})$ in ten patients and in only two healthy controls. We found a trend $(t=1,911$; $d f=46$; $\mathrm{p}=0,062$; Student's T-test) towards increased levels of factor VIII in patients with psychosis as compared with healthy volunteers. Laboratory data in patients and healthy volunteers are presented in Table 3.

\section{Discussion}

Venous thromboembolism may not always be adequately recognised in people with a severe mental disorder. Asymptomatic VTE, decreased interest in the maintenance of good health care by either patients or their physicians, a lack of collaboration between the patient and his physicians, the patient's distrust of other medical specialists who are not psychiatrists, and finally psychiatrists' limited knowledge concerning VTE diagnostics are factors that may contribute to the underdiagnosis of VTE in patients with mental illness. At the same time, the life of the patient may be at risk, especially in the case of pulmonary embolism [28].

Data in the literature concerning markers of thrombogenesis in unmedicated schizophrenic patients is limited. Iwata et al. [29] found increased levels of serum soluble L-selectin, but not sP-selectin, in 23 unmedicated patients with schizophrenia when compared with patients with major depression $(\mathrm{N}=17 ; \mathrm{P}=0.02)$ or healthy subjects $(\mathrm{N}=36 ; \mathrm{P}=0.005)$.

In a study by Walsh et al. [30], patients with schizophrenia $(\mathrm{N}=19)$ had increased platelet expression of surface receptors alpha(IIb) beta(IIIa) as compared with healthy controls $(\mathrm{N}=19 ; \mathrm{P}<0.0001)$, which may contribute to their increased risk for cardiovascular illness.

Morioka et al. [31] reported the cases of two patients (women who were 29 and 67 years of age, respectively) with psychiatric stupor who developed venous thrombosis. While dehydration, infection and decubitus ulcers are serious physical complications of psychiatric stupor, this condition also increases the risk of deep venous thrombosis.

Our findings suggest that acute psychosis may reflect a pro-coagulatory state. D-dimers are fragments of insoluble fibrin detectable in plasma after fibrin coagulum has been cleaved by plasmin. Increased plasma level of D-dimer results from pathological activation of blood clotting and occurs following fibrinolysis. Assessment of the D-dimer plasma level is important in clinical practice to exclude the diagnosis of deep vein thrombosis or pulmonary embolism, especially in the outpatient setting [32]. The specificity of D-dimers for the assessment of VTE is limited due to the fact that increased plasma levels can also be found in various kinds of inflammation, necrosis, tumours or infections. Nevertheless, we did not find any clinical or laboratory markers of infection in our sample of patients. The increased plasma level of D-dimer in acute psychosis may be a marker of fibrinolysis in the course of pathological blood clotting, when elevated epinephrine secretion stimulates the activation of thrombocytes [25,33]. Andreescu et al. [34] described D-dimer as a risk factor for deep vein thrombosis in the Leiden Thrombophilia Study. The authors studied the association of D-dimer with the risk of deep vein thrombosis in 474 patients who were more than six months out from the diagnosis of a first DVT and in 474 age- and sex-matched controls. For D-dimer levels above the 70 th percentile $(130.5 \mathrm{ng} / \mathrm{ml})$, the odds ratio (OR) for DVT was 2.2 (95\% CI 1.6-2.9).

The finding of elevated sP-selectin plasma levels as a marker of inflammation and increased thrombogenesis in our patients is consistent with the process described above. Thrombocytes are involved in atherogenesis if

Table 2 Demographic data on patients and healthy volunteers

\begin{tabular}{|c|c|c|c|c|c|c|c|}
\hline & \multicolumn{3}{|c|}{$\begin{array}{c}\text { Patients }(N=25 \\
\text { women } N=11)\end{array}$} & \multicolumn{3}{|c|}{ Healthy volunteers $(\mathrm{N}=25$; women $\mathrm{N}=12)$} & \multirow[b]{2}{*}{$\begin{array}{l}\text { p-value } \\
\text { (T-test) }\end{array}$} \\
\hline & Average (SD) & Median & Range & Average (SD) & Median & Range & \\
\hline Age (years) & $29.1(8.3)$ & 28 & $18-52$ & $29.3(8.3)$ & 28 & $19-53$ & NS \\
\hline Weight (kg) & $69.5(14.7)$ & 70 & $39-102$ & $72.4(12.7)$ & 67 & $55-101$ & NS \\
\hline BMI & $23.6(4.7)$ & 23 & $16.2-39.8$ & $23.5(2.6)$ & 23.5 & $19.3-29.6$ & NS \\
\hline $\begin{array}{c}\text { Duration of } \\
\text { untreated } \\
\text { psychosis (months) }\end{array}$ & $12.3(18.4)$ & 1.3 & $0.25-60$ & - & - & - & - \\
\hline
\end{tabular}

BMI - Body Mass Index, NS - non-significant, SD - standard deviation. T-test - Student's t-test 
Table 3 Laboratory assessments in patients and healthy volunteers

\begin{tabular}{|c|c|c|c|c|c|c|c|}
\hline & \multicolumn{3}{|c|}{ Patients ( $\mathrm{N}=25$ ) } & \multicolumn{3}{|c|}{ Healthy volunteers $(\mathrm{N}=25)$} & \multirow[b]{2}{*}{$\begin{array}{c}\text { p-value } \\
\text { (Test) }\end{array}$} \\
\hline & Average (SD) & Median & Range & Average (SD) & Median & Range & \\
\hline $\begin{array}{c}\text { D-dimers } \\
(\mathrm{mg} / \mathrm{l})\end{array}$ & $1.12(2.38)$ & 0.38 & $0.12-11.81$ & $\begin{array}{l}0.28 \\
(0.3) \\
\end{array}$ & 0.19 & $0.04-1.6$ & $\begin{array}{c}0.003 \\
(\mathrm{MW}-\mathrm{U})\end{array}$ \\
\hline Factor VIII (\%) & $\begin{array}{c}160 \\
(72.5) \\
\end{array}$ & 148 & $73-364$ & $\begin{array}{c}123 \\
(62.5) \\
\end{array}$ & 110 & $69-290$ & $\begin{array}{c}0.062 \\
\text { (T-test) }\end{array}$ \\
\hline $\begin{array}{l}\text { sP-selectin } \\
(\mathrm{ng} / \mathrm{ml})\end{array}$ & $209.9(124)$ & 204.1 & $63.3-654.4$ & $124.1(32)$ & 112.4 & $85.6-214.3$ & $\begin{array}{c}0.0005 \\
(\mathrm{MW}-\mathrm{U})\end{array}$ \\
\hline
\end{tabular}

MW-U - Mann-Whitney U Test, SD - standard deviation, T-test - Student's t-test

endothelial dysfunction is also present. The membrane pro-coagulatory protein sP-selectin is produced by activated thrombocytes [35]. sP-selectin induces migration and adhesion of leukocytes as well as stimulation of endothelial cells and thrombocytes. sP-selectin plays an important role as a connecting element between inflammation and thrombosis [36]. Not only have increased plasma levels of sP-selectin been found in patients with venous thromboembolism in a short time after the acute incident $[37,38]$, but they were also present after several months [39].

The median level of factor VIII coagulatory activity showed a trend towards being higher in patients than in healthy volunteers (median 148 versus 110\%; $\mathrm{U}=$ 216,500; $P=0.062$ ). The difference was statistically significant in the subgroups of women (psychotic versus healthy women; median 170 versus $111 \%$; $U=33,000$; $\mathrm{p}=0.042$ ). Twelve patients in contrast to six healthy volunteers had factor VIII coagulatory activity that was abnormally high (above 150\%). Increased blood levels of factors II, V, and VIII are associated with an increased risk of venous thromboembolism according to the current literature [40]. Individuals with factor VIII coagulatory activity above $150 \mathrm{IU} / \mathrm{dl}$ have a threefold risk of developing VTE as compared with subjects with activity $<150 \mathrm{IU} / \mathrm{dl}$; and they are six times more likely to develop this condition than people with activity $<100 \mathrm{IU} / \mathrm{dl}$. People with factor VIII coagulatory activity equal to $150 \mathrm{IU} / \mathrm{dl}$ are at a 2.7 -fold increased risk of venous thromboembolism when compared with the general population [41].

The authors are aware of limitations of the results. The study sample is small, so the results may only be considered as preliminary at this moment. The generalisibility of the findings may also be limited by the disease heterogeneity in psychosis.

\section{Conclusions}

Since the 1950s, when the first antipsychotic medications were developed, there have been reports of an increased prevalence of venous thromboembolism in patients treated with antipsychotics. In the last decade, this topic has received increased attention within the scientific literature. The diagnoses of schizophrenia or bipolar affective disorder themselves as well as hospitalisation or stress-induced increases in sympathetic activation and catecholamine blood levels are also prothrombogenic factors. In our sample of unmedicated patients with acute psychosis, we found an increased level of blood markers of the pathological activation of blood clotting and fibrinolysis, as well as activation of thrombocytes when compared with matched healthy volunteers. Prospective studies are needed to elucidate the biological mechanisms involved in the relationship between venous thromboembolism and antipsychotic medication versus the mental disorder itself.

\section{Acknowledgements}

This study was supported by the Research Project of the Ministry of Health of the Czech Republic, MZO 00179906, and the Research Project of the Ministry of Education of the Czech Republic, MSM 0021620816.

\section{Author details}

'Dept. of Psychiatry, Charles University in Prague, Faculty of Medicine in Hradec Králové, and University Hospital Hradec Králové, Czech Republic. ${ }^{2} 1 s t$ Dept. of Internal Medicine, Charles University in Prague, Faculty of Medicine in Hradec Králové, and University Hospital Hradec Králové, Czech Republic. ${ }^{3}$ Institute of Clinical Immunology and Allergology, Charles University in Prague, Faculty of Medicine in Hradec Králové, and University Hospital Hradec Králové, Czech Republic. ${ }^{4}$ Dept. of Neurology, Charles University in Prague, Faculty of Medicine in Hradec Králové, and University Hospital Hradec Králové, Czech Republic.

\section{Authors' contributions}

$J M, R M$ and LH conceived of the study, participated in its design, collected data and drafted the manuscript. CA carried out the immunoassays and made substantial contributions to the analysis and interpretations of the data. MV helped draft the manuscript and participated in data collection. JB provided statistical analysis and made substantial contributions to the analysis and interpretation of the data. All authors read and approved the final manuscript.

\section{Competing interests}

The authors declare that they have no competing interests.

Received: 22 July 2010 Accepted: 3 January 2011

Published: 3 January 2011

\section{References}

1. Brown S: Excess mortality of schizophrenia. A metanalysis. Br J Psychiatry 1997, 171:502-508. 
2. Leucht S, Burkard T, Henderson J, Maj M, Sartorius M: Physical illness and schizophrenia: a review of the literature. Acta Psychiatr Scand 2007, 116:317-333

3. Joukamaa M, Heliövaara M, Knekt P, Aromaa A, Raitasalo R, Lehtinen V: Schizophrenia, neuroleptic mediaction and mortality. Br J Psychiatry 2006, 188:122-127

4. Osborn DP, Wright CA, Levy G, King MB, Deo R, Nazareth I: Relative risk of diabetes, dyslipidaemia, hypertension and the metabolic syndrome in people with severe mental illnesses: systematic review and metaanalysis. BMC Psychiatry 2008, 8:84.

5. Saha S, Chant D, McGrath J: A systematic review of mortality in schizophrenia. Is the differential mortality gap worsening over time? Arch Gen Psychiatry 2007, 64:1123-1131.

6. Weinmann S, Read J, Aderhold V: Influence of antipsychotics on mortality in schizophrenia: systematic review. Schizophr Res 2009, 113:1-11.

7. Osinbowale O, Ali L, Chi YW: Venous thromboembolism: a clinical review. Postgrad Med 2010, 122:54-65.

8. Rosendaal FR: Thrombosis in the young: epidemiology and risk factors. A focus on venous thrombosis. Thromb Haemost 1997, 78:1-6.

9. Virchow R: Phlebitis and thrombosis in the vascular system. Collected Works on Scientific Medicine Frankfurt: Staatsdruckerei; 1856.

10. Malý R, Masopust J, Hosák L, Konupčíková K: Assessment of risk of venous thromboembolism and its possible prevention in psychiatric patients. Psychiatry Clin Neurosci 2008, 62:3-8

11. DeHert M, Dekker JM, Wood D, Kahl KG, Holt RIG, Möller HJ: Cardiovascular disease and diabetes in people with severe mental illness position statement from the European Psychiatric Association (EPA), supported by the European Association for the Study of Diabetes (EASD) and the European Society of Cardiology (ESC). Eur Psychiatry 2009, 24:412-424.

12. Shi L, Ascher-Svanum $H$, Chiang YJ, Zhao Y, Fonseca V, Winstead D: Predictors of metabolic monitoring among schizophrenia patients with a new episode of second-generation antipsychotic use in the Veteran Health Administration. BMC Psychiatry 2009, 9:80.

13. Hägg S, Spigset O: Antipsychotic-induced venous tromboembolism: a review of the evidence. CNS Drugs 2002, 16:765-776.

14. Zornberg Gl, Jick H: Antipsychotic drug use and risk of first-time idiopathic venous thromboembolism: a case control study. Lancet 2000, 356:1219-1223.

15. Liperoti R, Pedone C, Lapane KL, et al: Venous thromboembolism among eldery patients treated with atypical and conventional antipsychotic agents. Arch Intern Med 2005, 165:2677-2682.

16. Lacut K, Le Gal G, Couturaud F, Cornily G, Leroyer C, Mottier D, Oger E: Association between antipsychotic drugs, antidepressant drugs and venous thrmoboembolism: results from the EDITH case-control study. Fundam Clin Pharmacol 2007, 21:643-650.

17. Jönsson AK, Brudin L, Ahlner J, Hedenmalm K, Ericsson A, Hägg S: Antipsychotics associated with pulmonary embolism in a Swedish medicolegal autopsy series. Int Clin Psychopharmacol 2008, 23:263-268.

18. Jönsson AK, Horváth-Puhó E, Hägg $S$, Pedersen L, Sorensen HT: Antipsychotics and risk of venous thromboembolism: A populationbased case-control study. Clin Epidemiol 2009, 1:19-26.

19. Kamijo Y, Soma K, Nagai T, Kurihara K, Ohwada T: Acute massive pulmonary thromboembolism associated with risperidone and convetional phenothiazines. Circ J 2003, 67:46-48.

20. Waage IM, Gedde-Dahl A: Pulmonary embolism possibly associated with olanzapine treatment. BMJ 2003, 327:384

21. Hägg S, Tatting P, Spigset O: Olanzapine and venous thromboembolism. Int Clin Psychopharmacol 2003, 18:299-300.

22. Borras $L$, Eytan A, de Timary P, Constant EL, Huguelet $P$, Hermans $C$ Pulmonary thromboembolism associated with olanzapine and risperidone. J Emerg Med 2007, 35:159-161.

23. Malý R, Masopust J, Hosák L, Urban A: Four cases of venous thromboembolism associated with olanzapine. Psychiatry Clin Neurosci 2009, 63:116-118.

24. Hägg S, Bate A, Stahl M, Spigset O: Associations between venous thromboembolism and antipsychotics. A study of the WHO database of adverse drug reactions. Drug Saf 2008, 31:685-694.

25. Lazarus A: Physical restraints, thromboembolism, and death in 2 patients. J Clin Psychiatry 2001, 63:207-208.

26. Hägg $S$, Jönsson AK, Spigset O: Risk of venous thromboembolism due to antipsychotic drug therapy. Expert Opin Drug Saf 2009, 8:537-547.
27. World Health Organisation: International Statistical Classification of Diseases and Related Health Problems. 10th Revision. Version for 2007. Geneva 2006.

28. Rosendaal FR: Risk factors for venous thrombotic disease. Thromb Haemost 1999, 82:610-619.

29. Iwata Y, Suzuki K, Nakamura K, Matsuzaki H, Sekine Y, Tsuchiya K, Sugihara G, Kawai M, Minabe Y, Takei N, Mori N: Increased levels of serum soluble L-selectin in unmedicated patiens with schizophrenia. Schizophr Res 2007, 89:154-160

30. Walsh MT, Ryan M, Hillmann A, Condren R, Kenny D, Dinan T, Thakore JH: Elevated expression of integrin alpha(Illb) beta(IIla) in drug-naïve, firstepisode schizophrenic patients. Biol Psychiatry 2002, 52:874-879.

31. Morioka H, Nagatomo I, Yamada K, Horikiri Y, Okamura H, Takigawa M: Deep venous thrombosis of the leg due to psychiatric stupor. Psychiatry Clin Neurosci 1997, 51:323-326.

32. Ginsberg JS, Wells PS, Kearon C, Anderson D, Crowther M, Weitz Jl, Bormanis J, Brill-Edwards P, Turpie AG, MacKinnon B, Gent M, Hirsh J: Sensitivity and specificity of a rapid whole-blood assay for D-dimer in the diagnosis of pulmonary embolism. Ann Intern Med 1998, 129:1006-1011.

33. Hindersin P, Siegmund R, Körting HJ: Thrombophiliac diatheses as disorders of haemostasis in acute psychosis. Psych Neurol Med Psychol 1984, 36:702-709.

34. Andreescu ACM, Cushman M, Rosendaal FR: D-Dimer as a risk factor for deep vein thrombosis: The Leiden thrombophilia study. Thromb Haemost 2002, 87:47-51

35. Mathur A, Robinson MS, Cotton J, Martin JF, Erusalimsky JD: Platelet reactivity in acute coronary syndromes: evidence for differences in platelet behaviour between unstable angina and myocardial infarction. Thromb Haemost 2001, 85:989-994.

36. Ay C, Jungbauer LV, Sailer T, Tengler T, Koder S, Kaider A, Panzer S, Quehenberger P, Pabinger I, Mannhalter C: High concentrations of soluble P-selectin are associated with risk of venous thromboembolism and the P-selectin Thr715 variant. Clin Chem 2007, 53:1235-1243.

37. Smith A, Quarmby JW, Collins M, Lockhart SM, Burnand KG: Changes in the levels of soluble adhesion molecules and coagulation factors in patients with deep vein thrombosis. Thromb Haemost 1999, 82:1593-1599.

38. Rectenwald JE, Myers DD Jr, Hawley AE, Longo C, Henke PK, Guire KE, Schmaier AH, Wakefield TW: D-dimer, P-selectin, and microparticles: novel markers to predict deep venous thrombosis. A pilot study. Thromb Haemost 2005, 94:1312-1317.

39. Blann AD, Noteboom WM, Rosendaal FR: Increased soluble P-selectin levels following deep venous thrombosis: cause or effect? Br J Haematol 2000, 108:191-193.

40. Cushman M: Epidemiology and risk factors for venous thrombosis. Semin Hematom 2007, 44:62-69.

41. Koster T, Blann AD, Briet E, Vandenbroucke JP, Rosendaal FR: Role of clotting factor VIII in effect of von Wilebrand factor on recurrence of deep-vein thrombosis. Lancet 1995, 345:152-155.

\section{Pre-publication history}

The pre-publication history for this paper can be accessed here: http://www.biomedcentral.com/1471-244X/11/2/prepub

doi:10.1186/1471-244X-11-2

Cite this article as: Masopust et al:: Markers of thrombogenesis are activated in unmedicated patients with acute psychosis: a matched case control study. BMC Psychiatry 2011 11:2 